\title{
BMJ Open Patient experience studies in the circumpolar region: a scoping review
}

\author{
Christine Ingemann (D) , ${ }^{1,2}$ Nathaniel Fox Hansen, ${ }^{3}$ Nanna Lund Hansen, ${ }^{1}$ \\ Kennedy Jensen, ${ }^{4}$ Christina Viskum Lytken Larsen, ${ }^{1,2}$ Susan Chatwood ${ }^{5}$
}

To cite: Ingemann $\mathrm{C}$, Hansen NF, Hansen NL, et al. Patient experience studies in the circumpolar region: a scoping review. BMJ Open 2020;10:e042973. doi:10.1136/ bmjopen-2020-042973

- Prepublication history and additional material for this paper is available online. To view these files, please visit the journal online (http://dx.doi.org/10. 1136/bmjopen-2020-042973).

$\mathrm{Cl}$ and $\mathrm{NFH}$ are joint first authors.

Received 21 July 2020 Revised 25 August 2020 Accepted 26 August 2020

Check for updates

(C) Author(s) (or their employer(s)) 2020. Re-use permitted under CC BY-NC. No commercial re-use. See rights and permissions. Published by BMJ.

${ }^{1}$ National Institute of Public Health, University of Southern Denmark Faculty of Health Sciences, Copenhagen,

Denmark

${ }^{2}$ Institute of Nursing and Health Sciences, University of Greenland, Nuuk, Greenland

${ }^{3}$ Tufts University School

of Medicine, Boston,

Massachusetts, USA

${ }^{4}$ Geisel School of Medicine at Dartmouth, Hanover, New Hampshire, USA

${ }^{5}$ University of Alberta School of Public Health, Edmonton, Alberta, Canada

Correspondence to Christine Ingemann chin@sdu.dk

\begin{abstract}
Objectives Patient experiences with health systems constitute a crucial pillar of quality care. Across the Arctic, patients' interactions with the healthcare system are influenced by challenges of access, historical inequities and social determinants. This scoping review sought to describe the range and nature of peer-reviewed literature on patient experience studies conducted within the circumpolar region.
\end{abstract}

Design In a partnership between Danish/Greenlandic, Canadian and American research teams, a scoping review of published research exploring patient experiences in circumpolar regions was undertaken.

Data sources Seven electronic databases were queried: MEDLINE, Embase, Scopus, 'Global Health 1910 to 2019Week 11', CINAHL, PsycINF0 and SveMed+.

Eligibility criteria Articles were eligible for inclusion if they (a) took place in the circumpolar region, (b) reported patients' perspective and (c) were focussed primarily on patient experiences with care, rather than satisfaction with treatment outcome.

Data extraction and synthesis Title and abstract screening, full-text review and data extraction was conducted by four researchers. Bibliometric information such as publication date and country of origin was extracted, as was information regarding study design and whether or not the article contained results relevant to the themes of Indigenous values, rural and remote context, telehealth and climate change. Two researchers then synthesised and characterised results relevant to these themes.

Results Of the 2824 articles initially found through systematic searches in seven databases, 96 articles were included for data extraction. Findings from the review included unique features related to Indigenous values, rural and remote health, telehealth and climate change. Conclusions The review findings provide an overview of patient experiences measures used in circumpolar nations. These findings can be used to inform health system improvement based on patient needs in the circumpolar context, as well as in other regions that share common features. This work can be further contextualized through Indigenous methodologies such as sharing circles and community based participatory methods.

\section{INTRODUCTION}

A growing body of research exploring patient experiences of care reveals that such measures not only capture level of satisfaction with care but also correlate with important
Strengths and limitations of this study

This scoping review represents the most comprehensive and detailed examination of existing literature on patient experiences in the circumpolar region.

- Our focus on four core features of circumpolarspecific patient experiences (Indigenous values, rural and remote, climate change and telehealth) provides a clear view of experience domains relevant to circumpolar populations, while allowing bottom-up synthesis of themes.

- A potential limitation of this study was that no external framework was used to guide data analysis, which limits the ability of these findings to dialogue directly with research in this field.

metrics including clinical outcomes and patient safety. ${ }^{1}$ Targeted attempts to improve patient experiences have led to quantitative improvements in health outcomes. ${ }^{2}$ Additionally, positive patient experiences have been linked to high satisfaction among medical teams-a critical factor in the prevention of burnout and workforce attrition.

The experiences of patients in health systems can be reflective of the challenges and privileges they experience in daily life. Racial and ethnic minorities, as well as rural and low-income populations continue to experience suboptimal health outcomes, due in part to the effect of institutionalised racism and structural poverty on their ability to access and receive quality healthcare. ${ }^{4}$

Residents of the circumpolar North face these challenges as well, and while some northern populations compare favourably with the respective national average in terms of mortality rate for conditions such as diabetes, the relatively high rates of other conditions including heart disease and selfinflicted injury indicate significant disparities in health promotion and utilisation in the circumpolar North. ${ }^{5}$ Furthermore, the unique characteristics of the circumpolar region make the provision of quality healthcare especially challenging. Huot et 
$a t^{6}$ previously identified four themes that were unique to access to care in northern health systems: influence of physical geography, provider-related barriers, culture and language and the impact of systemic factors such as lack of funding.

A number of studies address similar themes, including one study of Sami patients in the Norwegian healthcare system that found a culturally unsafe environment and lack of interpreting services to be associated with patients receiving unequal access to health information. ${ }^{7}$ Additionally, a study involving First Nations, Inuit and Métis participants in Canada showed how the legacy of colonialism as well as contemporary exposures to culturally unsafe care impacted how engaged patients felt with their diabetes management. ${ }^{8}$

The circumpolar region is home to many Indigenous populations, where the unique historical, environmental and cultural dynamics contribute to the complexity of system-wide evaluation of patient experiences in the region. The predominant approaches to health system evaluation are rooted in a biomedical conception of health, though other approaches, such as postcolonial and traditional knowledge ideologies are beginning to become incorporated into mainstream health systems analysis. $^{9-13}$

Another defining feature of the circumpolar world is its sparse population distribution and the predominance of communities situated in remote areas. This presents challenges to the provision of safe and accessible healthcare. One study of rheumatoid arthritis patients in rural Canada found that travel distance as well as severe weather affecting travel negatively impacted their healthcare experience. ${ }^{14}$ However, the challenge of geographical remoteness also stimulates innovation; circumpolar areas are renowned for their pioneering implementation of telehealth technologies. ${ }^{15}$ Expanding use of telehealth for services such as chronic disease management ${ }^{16}$ and diagnostic imaging ${ }^{17}$ holds the potential for transformative health system changes, but it also brings with it novel barriers to the assessment of patient experiences. The increasing reliance on telehealth in circumpolar regions necessitates a review of patient experiences using these technologies.

The aim of this scoping review was to describe patient experience studies conducted within the circumpolar region, with the goal of elucidating factors that influence patient perceptions and utilisation of health services.

\section{METHODS}

A scoping review with a thorough systematic search and screening process was conducted. Though the search was planned in advance, no protocol was registered. Our methodology was informed by the scoping methods devised by Arksey and O'Malley ${ }^{18}$ and as such, our goal was to provide a broad overview of the extent and range of literature relevant to patient experiences in circumpolar populations. Scoping reviews have been successfully used to better understand health topics in circumpolar regions. ${ }^{19-21}$ Our work does not assess the quality of included articles, but aims to provide a preliminary picture of what has been published across Arctic regions with shared experiences. In this review, analysis was conducted across dimensions of patient experiences related to the shared features of Indigenous values, rural and remote geography, climate change and telehealth, as these categories are of particular importance to circumpolar health systems given the specific challenges and characteristics of the circumpolar region. Publications that did not address these categories were still included. This allowed for broad capture of relevant publications and bottom-up synthesis of themes.

\section{Patient and public involvement}

No patient involved. Patient engagement in future phases is discussed in the conclusions.

\section{Focus population}

The focus population of the review was the population living in the circumpolar region, which is home to many Indigenous populations. ${ }^{22}$ The circumpolar region was defined geographically by definitions used in an international circumpolar health systems comparison. ${ }^{15}$ Additional regions considered circumpolar were made based on Indigenous regions represented through international forums such as the Arctic Council. ${ }^{23}$ A circumpolar health sciences librarian made some alterations to the boundaries used for circumpolar geography in the search (figure 1).

\section{Search strategy}

Preliminary searches were conducted by both the American/Canadian team and the Danish/Greenlandic team, before combining search terms and refining them in collaboration with the librarians. This lead to a comprehensive search syntax based on the two key concepts, namely 'patient experience' (searched in 'all fields') and 'circumpolar region/population' (searched in 'title, abstract and keywords'). The full search strings are available in online supplemental file 1.

Searches in seven electronic databases were conducted on $27^{\text {th }}$ March 2019: MEDLINE, Embase, Scopus, 'Global Health 1910 to 2019 Week 11', CINAHL, PsycINFO and SveMed+. Only in the database SveMed+ a small adjustment of the search string was necessary to be applied in the search machine. The search had no limited time frame.

\section{Screening and selection process}

The search result of the databases was imported to the online review programme Covidence,${ }^{24}$ where duplicates were screened and excluded by the programme and an additional hand-search for duplicates was performed. The whole screening process of the review was conducted in Covidence by four researchers under the supervision of two senior advisors. 


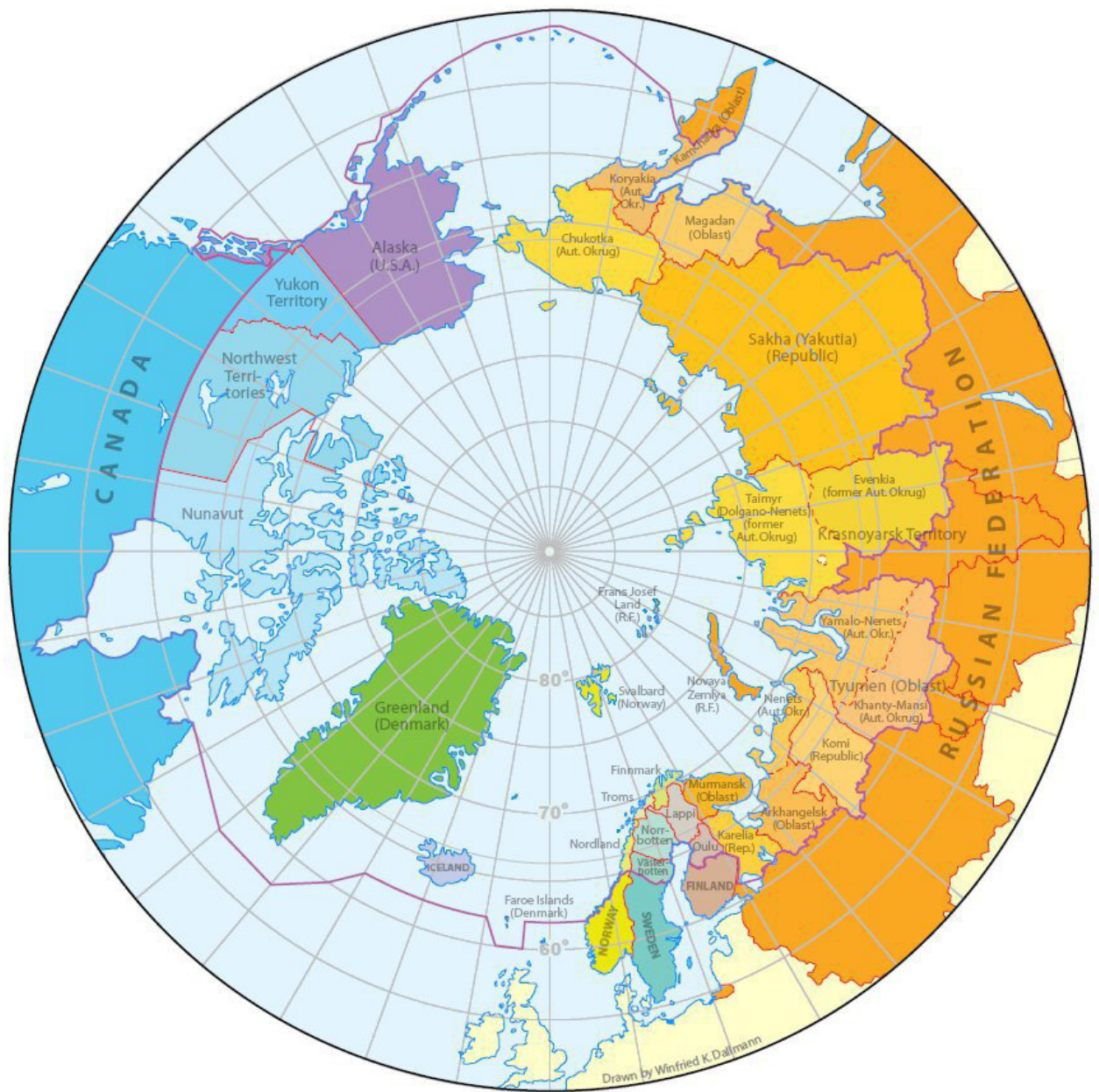

Figure 1 Map of the circumpolar North and its regions. Map by Winfried Dallmann, Norwegian Polar Centre.

Eligibility criteria were developed for the title and abstract screening, and refined for the full-text screening. In the title and abstract screening, articles were eligible if: a. Study participants included northern or Indigenous populations.

b. Studies reported the patient perspective.

c. Studies on all areas of patient experiences in the healthcare system from a specific illness to health promotion activities, excluding perceptions of health research and specific treatment outcome.

For the full-text screening criteria were made more explicit, and articles were excluded if:

a. The study did not take place in the circumpolar region or focus specifically on care experience of circumpolar population.

b. Less than $5 \%$ of study participants were from the circumpolar region.

c. Patient experience pertained to outcome rather than care experience.

d. The study failed to directly measure patient experiences.

In the full-text screening, the full-text of 10 articles were not accessible, and original authors and journals could not be reached, therefore these articles were excluded.
Extracted data included bibliometric information, study design, method, location, reason for seeking treatment, general themes from each article and whether or not the article had a focus in Indigenous values, rural and remote geography, climate change, and telehealth. These latter categories were selected because of their special relevance to the health experiences of circumpolar populations. Two independent librarians conducted an external validation of the literature search. Each article was reviewed at every stage of screening by two of the four reviewers. Extracted information to the Excel sheet was also reviewed by a second person in the review team. The screening and selection process are visualised in the PreferredReporting Items for Systematic Reviews and Meta-Analyses (PRISMA) diagram in figure 2, and a corresponding PRISMA checklist was completed during review (see online supplemental file 2).

\section{RESULTS}

\section{Bibliometric results}

A total of 96 peer-reviewed articles were identified. The oldest study on patient perspectives and experiences included in this review dates back to $1989{ }^{25}$ The number 


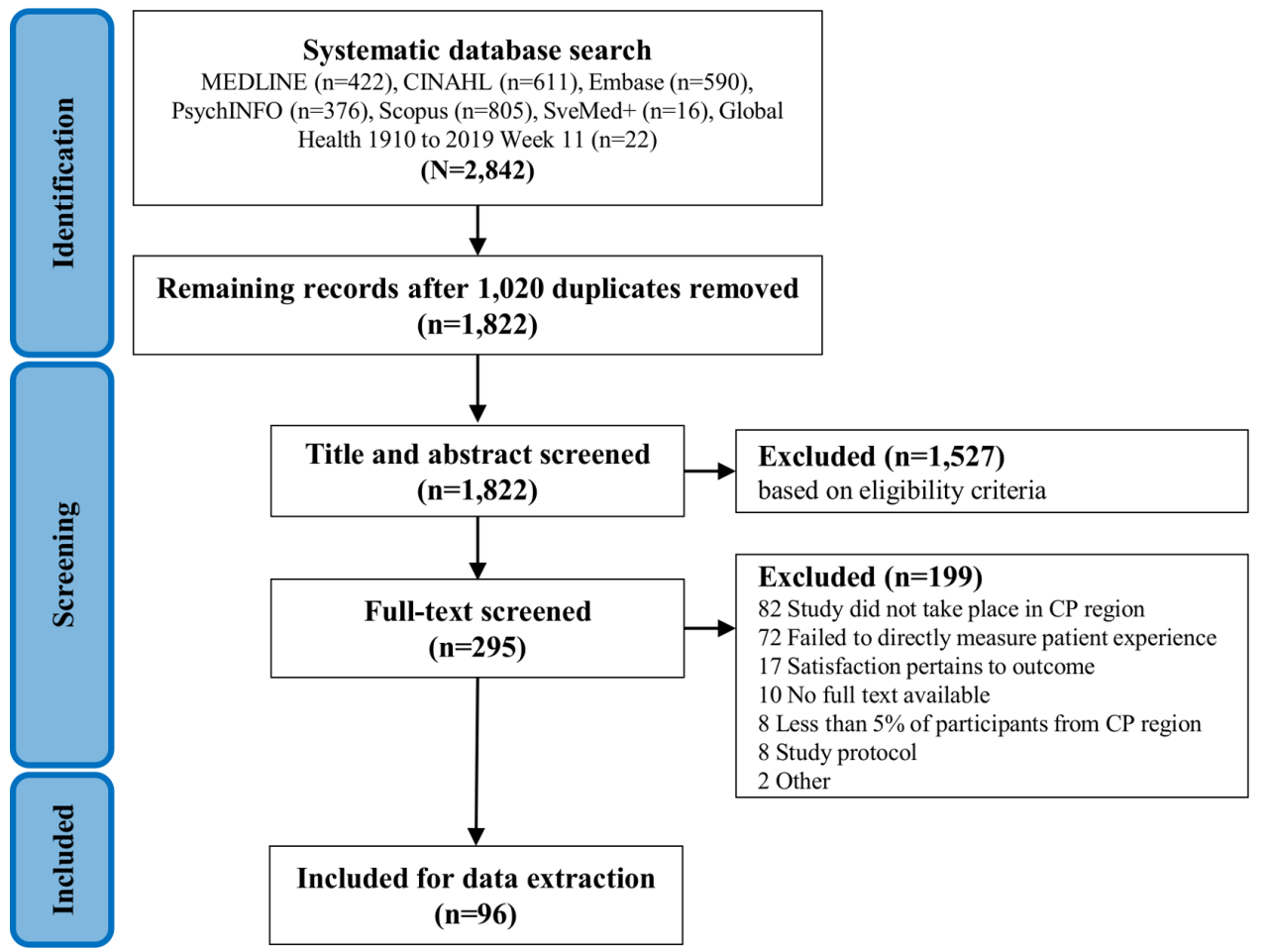

Figure 2 PreferredReporting Items for Systematic Reviews and Meta-Analyses (PRISMA) of the screening process. CP, circumpolar.

of patient experience studies roughly doubled each decade thereafter (table 1 ). Three quarters of the studies took place in Iceland $(\mathrm{n}=24),{ }^{26-49}$ Norway $(\mathrm{n}=24)^{49-72}$ and Sweden $(\mathrm{n}=22){ }^{17}{ }^{47-49}{ }^{73-90}$ Nineteen studies were from North America; Canada $(\mathrm{n}=10)^{25} 91-99$ and Alaska (USA) $(\mathrm{n}=9) .{ }^{16}{ }^{100-107}$ Five or less studies took place in Finland $(\mathrm{n}=5),{ }^{4748108-110}$ Greenland $(\mathrm{n}=4),{ }^{11-114}$ Russia $\left.(\mathrm{n}=3)\right)^{115-117}$ and the Faroe Islands $(n=1) .{ }^{118}$ Three articles included study results from more than one country. ${ }^{47-49}$ Half of the identified studies applied a quantitative research design with surveys as their only data collection method $(\mathrm{n}=47) .{ }^{1726-364750-6273-839192100-102} 108-110115116$ Forty articles

\begin{tabular}{|c|c|c|c|c|c|}
\hline $\begin{array}{l}\text { Year of } \\
\text { publication }\end{array}$ & & $\begin{array}{l}\text { Country of } \\
\text { study }\end{array}$ & & Study design & \\
\hline 2010-2019 & 52 & Iceland & 24 & Quantitative & 47 \\
\hline 2000-2009 & 27 & Norway & 24 & Qualitative & 40 \\
\hline 1989-1999 & 17 & Sweden & 22 & $\begin{array}{l}\text { Mixed- } \\
\text { methods }\end{array}$ & 9 \\
\hline $\begin{array}{l}\text { Language of } \\
\text { article }\end{array}$ & & Canada & 10 & $\begin{array}{l}\text { Methods } \\
\text { applied in } \\
\text { study }\end{array}$ & \\
\hline English & 87 & Alaska (USA) & 9 & Survey & 56 \\
\hline Norwegian & 6 & Finland & 5 & Interview & 40 \\
\hline Danish & 1 & Greenland & 4 & Focus groups & 9 \\
\hline Icelandic & 1 & Russia & 3 & Text analysis & 6 \\
\hline Finnish & 1 & Faroe Islands & 1 & $\begin{array}{l}\text { Participant } \\
\text { observation }\end{array}$ & 3 \\
\hline
\end{tabular}

applied a solely qualitative research design of which 29 used only interview as a method, ${ }^{37-434863-7084-8693-97103104111112118}$ 6 applied only focus group discussions $(n=4)^{164471117}$ or text analysis $(\mathrm{n}=2)^{87105}$ as a method and 5 studies applied various qualitative methods. ${ }^{25} 8898113114$ Nine studies applied mixed methods (mix of quantitative and qualitative methods) of which six used a combination of a survey and interviews, ${ }^{46} 729099106107$ two survey and text analysis $^{4989}$ and one survey and focus group discussions. ${ }^{45}$

Quantitative studies were the most commonly used study design in Sweden $(\mathrm{n}=13),{ }^{1749} 73-83$ Norway $(\mathrm{n}=13)^{50-62}$ and Iceland ( $n=12),{ }^{26-36} 49$ and less than half of the studies in these three Scandinavian countries applied qualitative methods (figure 3). Qualitative methods were largely found in Alaska $(n=4),{ }^{16}{ }^{103-105}$ Canada $(n=7),{ }^{25} 93-98$ Greenland $(\mathrm{n}=4)^{111-114}$ and the Faroe Islands $(\mathrm{n}=1) .{ }^{118}$

The identified studies were further categorised into the different disease groups based on the focus or included patient group in the studies. Nearly one-fifth of the studies did not focus on a specific illness and were categorised as general (figure 4). These general studies typically took the form of a patient experience survey sent to a random sample of citizens or patients in a particular region or hospital network $(\mathrm{n}=18)$. $^{25} 555764738789$ 97-102 104109111115 Other common areas of patient care where patient experience studies were conducted were in maternal health $(\mathrm{n}=13),{ }^{28} 333748497678799093105112116$ primary healthcare $(\mathrm{n}=12),{ }^{16} 1736405456597477828395$ mental health and addiction $(\mathrm{n}=9), \begin{array}{lllllllll}41 & 46 & 58 & 66 & 67 & 80 & 91 & 110 & \text { cancer }\end{array}$ $(\mathrm{n}=8),{ }^{34383950103106113114}$ emergency $(\mathrm{n}=8)^{303575858894108118}$ and surgery $(n=6) .{ }^{264752606570}$ Less than five studies were 


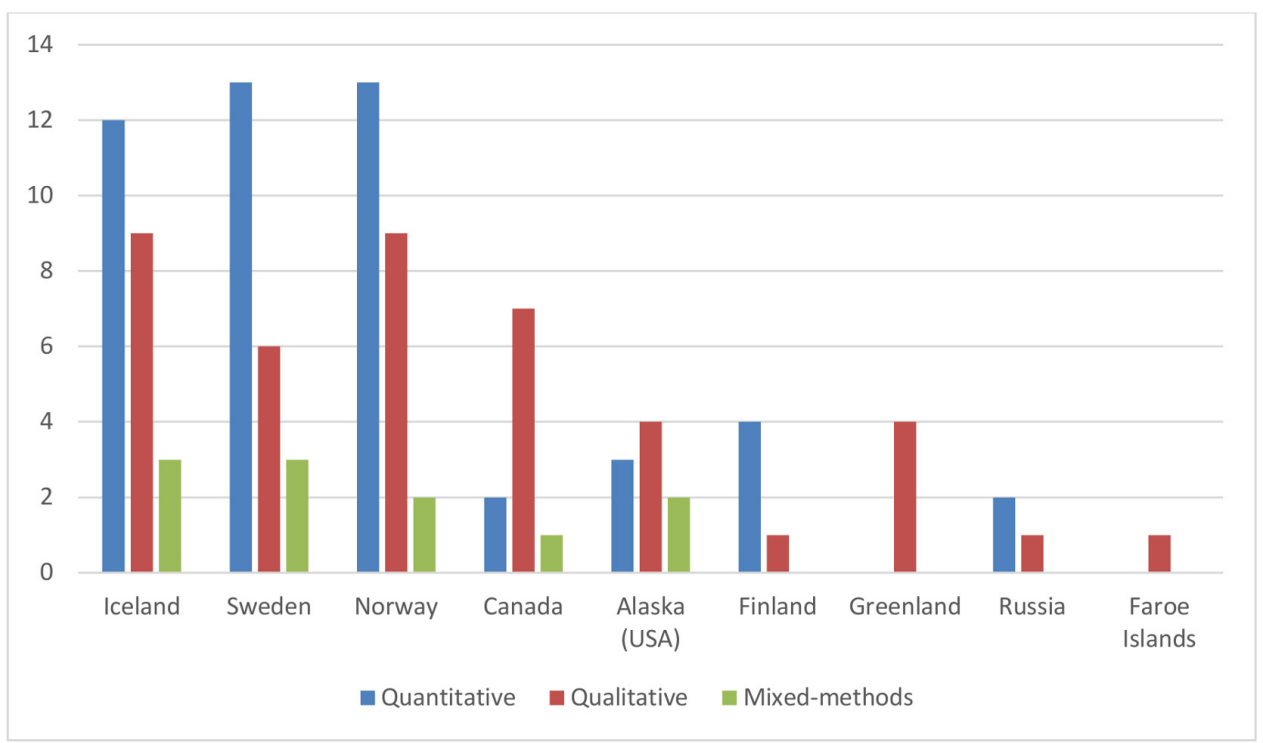

Figure 3 Country by study design ( $n=102), 3$ of the 96 studies included three countries.

identified in each of the remaining nine areas (figure 4). Studies of primary healthcare, surgery, pain, headache and paediatric issues were more likely to use quantitative methodologies whereas studies of cancer, geriatric health, diabetes, disability and pharmacy issues were more likely to rely on qualitative methodologies (figure 4). Studies of general health issues, maternal/child health, mental health/addiction, emergency and communicable disease used quantitative and qualitative methodologies in approximately equal measure. See also online supplemental file 3 for extraction table and detailed overview of the articles.

\section{Thematic results}

Over half of the included articles $(n=49)$ did not focus on any of the four predefined categories that were thought to be characteristic of circumpolar health systems: Indigenous values, rural/remote health, climate change or telehealth. Figure 5 and figure 6 provide an overview of the 47 articles that account for findings valuable to the circumpolar-specific patient experience categories. The remaining studies related to patient perspectives and experiences with healthcare services were included in the general analysis of patient experiences studies.

It was noteworthy that every Canadian and Greenlandic article contained at least one predefined circumpolar patient experience factor: Indigenous values, rural and remote healthcare, climate change or telehealth. Seven out of 9 articles from Alaska (USA) $(77 \%),{ }^{16100-102} 10410610716$ out of 24 articles from Norway $(67 \%),{ }^{49}{ }^{55-62} 66-72 \quad 2$ out of 5 articles from Finland $(40 \%),{ }^{109110} 1$ out of 3 articles from Russia $(33 \%),{ }^{117} 6$ out of 22 articles from Sweden $(27 \%)^{1781-838790}$ and 2 out of 24 articles from Iceland $(8 \%)^{4445}$ contained at least one of these factors, while the article from Faroe Islands

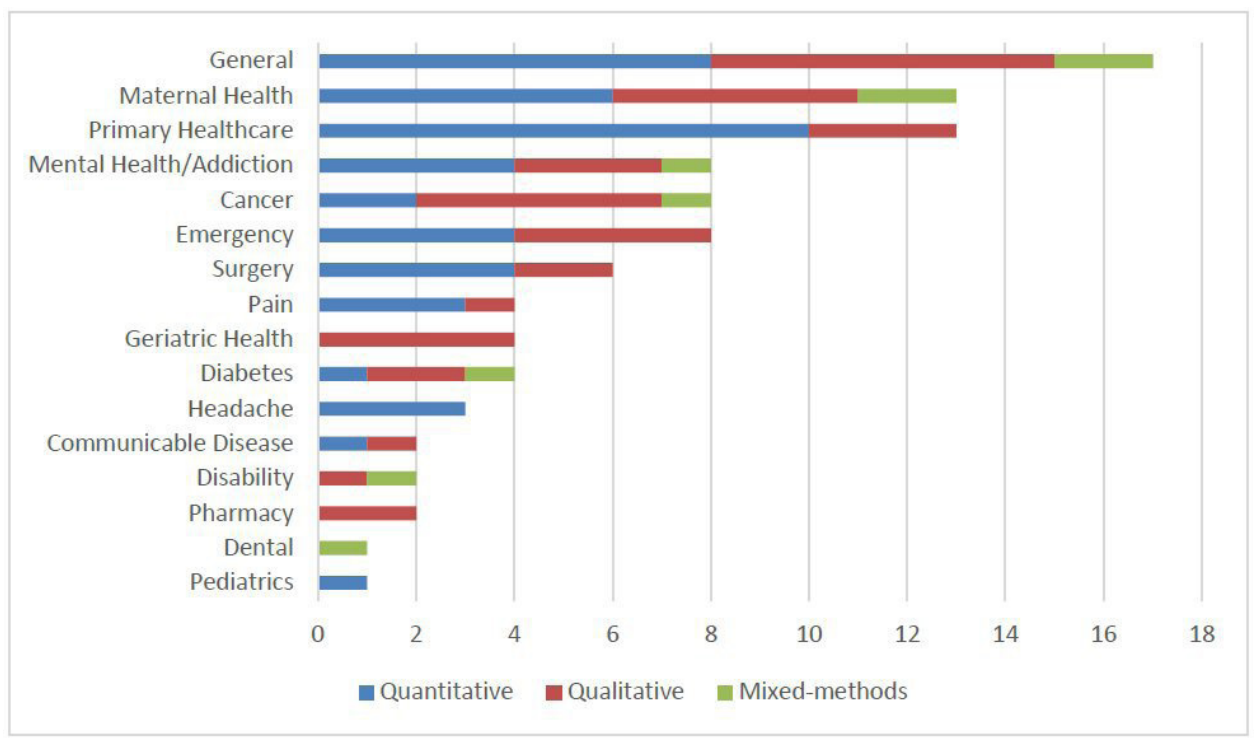

Figure 4 Reason for seeking care by study design ( $n=96)$. 


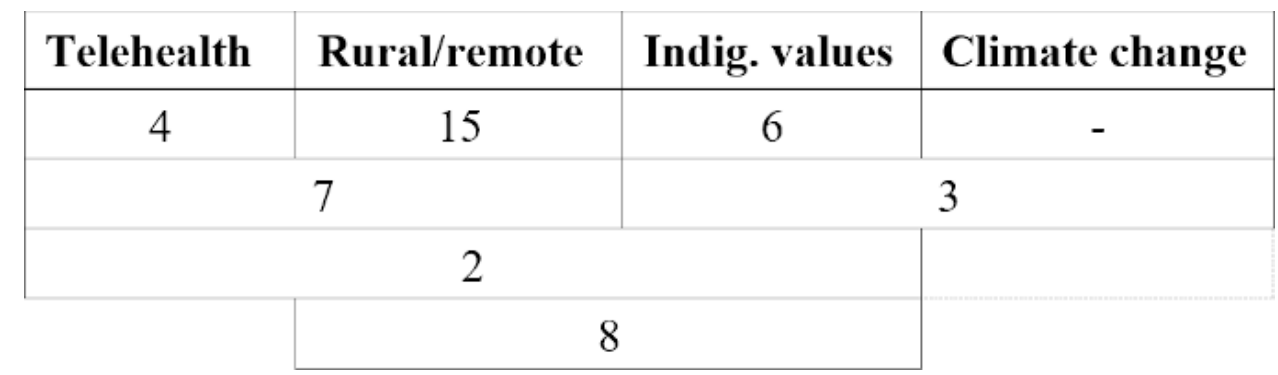

Figure 5 Studies containing one or more of the four predefined categories $(n=47)$

contained none of the factors. Of the predefined circumpolar issues, rural and remote healthcare was the most commonly captured factor $(\mathrm{n}=36),{ }^{16} 1725444555-5759-626671$ 72819091 93-102 $104106107110-112114117$, values $(n=21),{ }^{16} 25585967-6971829294-99107111-114$ telehealth

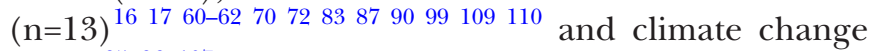
$(\mathrm{n}=3) .9596107$ Results relevant to the four predefined themes are summarised below.

Rural/remote and telehealth

Receiving care in one's home community, geographical proximity and the possibility to save costs and time for not having to travel to urban areas for healthcare services, were aspects important to positive patient experiences. ${ }^{16} 1744555660-62729093100104{ }^{106}$ In the 13 studies investigating patient experiences with telehealth, patients responded that telehealth had obviated the need for travel or that even if telehealth had limitations, they would still prefer teleconsultation from having to travel far distances. ${ }^{17} 60728390102110$ One Swedish study found that patients experienced that the waiting times for telehealth calls were too long, ${ }^{87}$ while a study in Finland found that patients felt they cut waiting time and were enabled to access quality care faster. ${ }^{109}$

Experiences with telemedical devices were diverse among the identified studies. Three studies noted that patients appreciated the presence of more than one health worker in the consultation, which gave them the experience of a more thorough consultation. ${ }^{60} 6270$ Patients in other studies doubted professionals' ability to diagnose certain diseases without physical contact. ${ }^{160}$ They were in some cases able to follow the examination on the screen, ${ }^{60} 70$ while others were uncomfortable appearing on the screen. ${ }^{60}$ Negative experiences with telemedical consultations were linked to not being able to build a personal relationship with the professional on the other side of the screen ${ }^{1670}$ or participants in the consultation not introducing themselves. ${ }^{90} 109$ Lastly, some studies on satisfaction with telehealth consultations found that patients saw further potential if technology was improved. ${ }^{1690}$

Negative patient experiences or issues related to receiving care in urban areas despite having to travel far were unstable or lack of physician coverage, ${ }^{55-5759} 95106$ perceived disparities in accessibility to high quality healthcare in rural regions, ${ }^{25} 4591101$ limited services offered in rural areas, ${ }^{55} 7195104$ poor continuity in care or not being able to build a relationship with the provider lead to insecurity among patients and thereby decreased use of health services ${ }^{81}$ lack of accommodation for patients and family members when treated in urban areas, ${ }^{94} 98102$ and being overwhelmed and disoriented when travelling to unknown urban areas. ${ }^{69} 98$

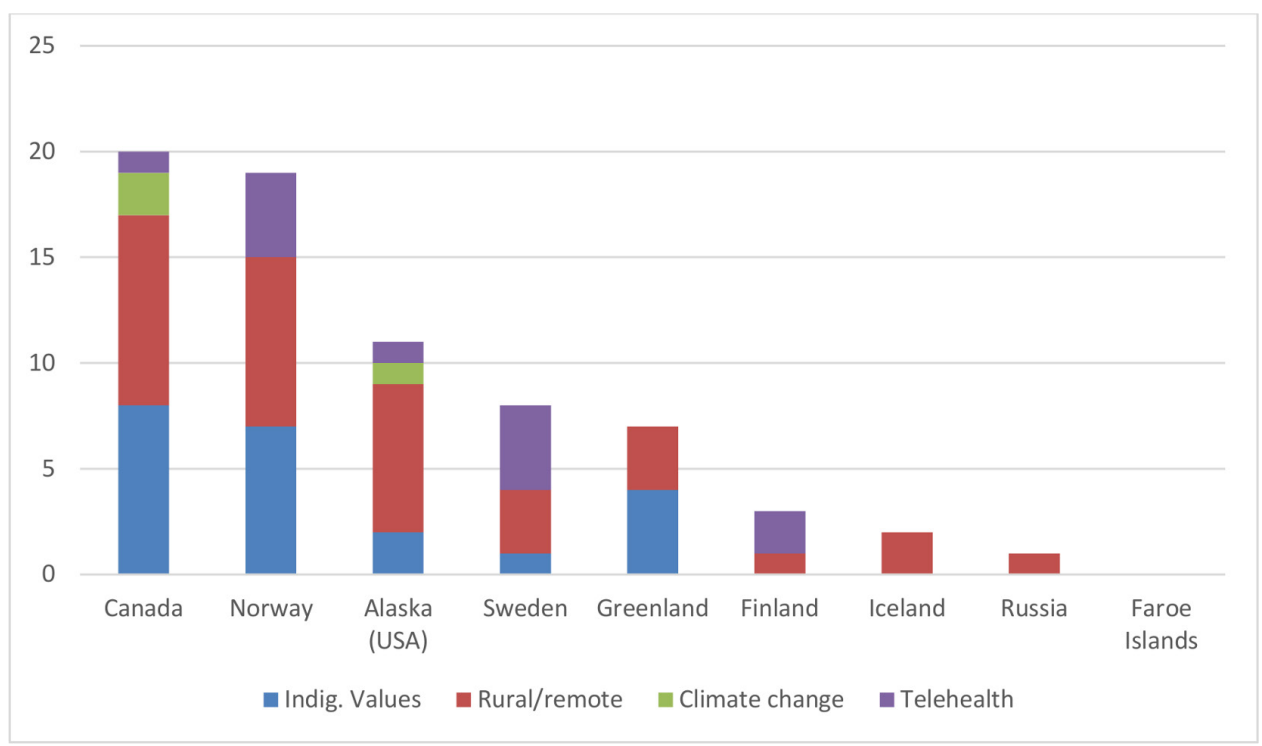

Figure 6 Country by category $(n=47)$. 
The 15 qualitative studies gave more nuanced patient experiences. Studies from Greenland and Canada with Inuit patients found that not being treated in their home community gave patients the feeling of being isolated and cut-off, as well as feeling out of their natural rhythm and tradition. ${ }^{94} 9599104111112114$ In one of these studies this was also associated with the context of colonial history ${ }^{99}$ Having to leave one's family and life in order to access care also lead to destabilising situations such as patients missing work. ${ }^{95} 112$ Not having immediate access to services made patients in rural areas feel unsafe. ${ }^{95}$ Levels of trust that rural patients felt towards local healthcare workers varied across different studies, with some patients worrying about the risk of gossiping in small communities. ${ }^{66} 9395-97$ A study from Russia assessing the diagnostic delay of tuberculosis found that patients in rural areas described physicians to not be equipped with the competencies required for practice in the region, and they did not expect 'good doctors' wanting to serve their communities, which influences their choice of accessing care. ${ }^{117}$ Another remote challenge in relation to healthcare discussed, was the difficulty of being able to access healthy food, which often was a recommendation or part of a treatment given by physicians. ${ }^{96} 107$

\section{Indigenous values and climate change}

A majority of the studies presenting aspects related to Indigenous values used qualitative methods ( 15 of 21). Aspects of patient experiences categorised as being a characteristic for Indigenous values related overall to being able to receive information in their Indigenous language and the availability of a good translator, ${ }^{16} 255967697194-99112113$ health professionals and services being culturally responsive, ${ }^{162567718292111}$ recognising traditional medicine or having a holistic perspective in care, ${ }^{58} 82949697114$ and when hospitalised, having access to traditional food, nature, social and cultural activities. ${ }^{68} 69949698107114$

Patients in studies from Greenland and Canada stated issues with not being able to receive information in their Indigenous language in consultations, pamphlets or signs in the health centres. ${ }^{94} 98112113$ This was also linked with poor provision of good quality interpreters. ${ }^{25} 59699899111113$ In a Norwegian study, Sami patients felt that some medical terms did not exist in the Sami language, which challenged the patient-provider conversation. ${ }^{67}$ Many studies conducted in areas with Sami populations reported Sami patients to have had negative experiences with healthcare providers not knowing and respecting their culture and customs $^{596769}$ enhancing existing mistrust from the colonial history. ${ }^{71} 82$

Meaningful activities and access to traditional foods were important to patient experiences when hospitalised. A Norwegian study focussing on the benefits of providing traditional foods in dementia care, resulted in increased well-being and improved appetite among patients. ${ }^{68}$ This was also experienced by Inuit patients in a Canadian study. ${ }^{98}$ Three articles ${ }^{69} 9698$ reported the healthpromoting benefits of time spent on the land. Of these,
Hanssen ${ }^{69}$ described how medical institutions often lack opportunities for Indigenous people to engage with the 'natural rhythm of life' through outdoor activities or consumption of traditional food.

Only three studies using qualitative or mixed methods mentioned climate change as an aspect influencing patients' experiences in healthcare..$^{95} 107$ Bird et a ${ }^{96}$ described how climate change was making it harder for Inuit living on Baffin Island to hunt country food and maintain their diabetes treatment plans. ${ }^{96}$ Oosterveer and Young ${ }^{95}$ and Wetterhall et $a l^{107}$ noted how extreme weather conditions challenged patients' access to healthcare and transportation to hospital. These are aspects linked to climate change and circumpolar peoples' health experiences.

Studies with Inuit and Sami populations found that services were often too task-driven or medication-driven while lacking meaningful and patient-centred activities. ${ }^{58} 6994114$ Indigenous patients appreciated consultations where physicians listened instead of asking many questions. ${ }^{97}$

\section{Other patient experience aspects}

Over half of all articles discussed the influence of health professionals' attitudes towards the patient as a determinant of patient satisfaction. Good professional skills were described in studies as: acting professional and making the patient feel relaxed or calm, ${ }^{83}$ close monitoring, ${ }^{32} 3587$ professionals being confident and not seeming unsure in consultations, ${ }^{53}$ competence of midwife as well as their presence without focussing only on their tasks created a safe haven. ${ }^{3749}$

Professionals' competence for compassionate care and ability to show empathy further influence patients experience of care. ${ }^{39} 416387101 \quad 105$ This was described in studies as nurses' and physicians' ability to resolve uncertainty, ${ }^{39} 7781$ encouraging patients to ask questions and respecting patients' knowledge, ${ }^{29} 4287103$ meeting the patient's needs ${ }^{27334073}$ and being supportive. ${ }^{3745496478}$ Negative patient experiences were rooted in poor support, ${ }^{33} 4879$ indifference of staff towards patients or being ignored ${ }^{4053648992}$ and personnel having a negative attitude. ${ }^{40} 89$

Narratives from Norwegian community mental health centres pointed out an issue of power imbalance between male physicians and female patients. ${ }^{66}$ Three studies found that patients did not feel comfortable to disagree or express criticism towards a health professional, or experienced that complaints were not properly recognised and handled. ${ }^{25737489}$

Being respected as an individual and not only seen as a patient was associated with positive experi-

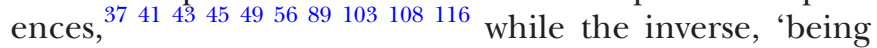
referred to as a diagnosis rather than person', ${ }^{89}$ was associated with negative experiences. Patients reported negative experiences when health personnel only read from the hospital record instead of listening to the patient ${ }^{87}$ and were poor in communicating. ${ }^{436094}$ Some studies' 
participants reported not having received sufficient information $^{26} 3045-475258647374767879939697113118$ leading to insecurity and vulnerability for some patients. ${ }^{76} 78113$ Consequently, gaining adequate and useful information was described to empower patients next to contribute to satisfaction. 283137404350546577808387105113

Promptness ${ }^{101}$ and not being in a rush but having time when being with the patient was important for patient experience; this was also linked to complaints about short appointment times. ${ }^{31} 374056878994111$ In nine studies long waiting times for treatment and appointment, as well as diagnostic delay were reported and influenced satisfaction of care negatively. 384651556475899394

Coordination of care and cooperation between professionals was also mentioned as adversely affecting the services patients received-the feeling of falling out of the system. ${ }^{4546648793106}$ In relation to this it was also important for patients to meet the same professionals in order to experience a greater continuity of care. ${ }^{34} 45$ Relatives' involvement in care and their support further contributes to a positive patient experience, ${ }^{36} 47808494$ since hospitalisation, for example, can lead to isolation and makes social support even more important. ${ }^{3841114}$

Other aspects criticised by patients were the cleanliness, structure and quality of the facilities, ${ }^{2674102115}$ lack of activities such as sports, parking spaces and heating systems, ${ }^{40} 4188$ hospital food, ${ }^{40}$ high costs such as medicines or even the lack of medicines. ${ }^{101115}$

\section{DISCUSSION}

This review aimed to scope the literature and identify peer-reviewed studies reporting on patient experiences of healthcare in the circumpolar region. We chose to use four predefined categories relevant to circumpolar health to provide structure to our results. These categories included rural and remote geography, telehealth, Indigenous values and climate change.

The most common descriptions of the rural and remote theme included patient experiences with travel costs, weather conditions influencing the ability to travel and lack of physicians influencing continuity of care. Increased accessibility of care and concerns about the ability to establish a personal relationship with providers were common descriptions relevant to the telehealth theme. Similarly, studies of Indigenous values in the experiences of healthcare included being able to speak one's own language during consultations, the difficulties of accessing an interpreter, access to traditional food and outdoor activities during hospitalisation, experiencing isolation from family and community when hospitalised and receiving holistic care.

This review demonstrates that rural and remote geography, telehealth, climate change and Indigenous values are highly relevant elements of circumpolar health systems. However, there are numerous other dimensions of care relevant to circumpolar populations that should be investigated further. One example is the relationship between patient experiences and the environment. Climate change was a predefined category but only mentioned in 3 out of 96 articles. In a study that took place in Nunavut, diabetes patients described how changes in the climate have affected the migratory habits of animals which has impeded their ability to procure traditional foods. This has made it more difficult for these patients to obtain healthy food that can be used to manage their diabetes. ${ }^{96}$ Other articles discussed how the increasing frequency of severe weather events has impacted patients travelling far distances to access treatment. ${ }^{95} 107$ Circumpolar literature has described the vulnerabilities of Indigenous and non-Indigenous peoples and the impacts of climate change on health and health systems. Impacts of climate change include changes in vectors of disease, emerging epidemics, food security, increases in land-based injury and mental health issues. ${ }^{119-123}$ Considering the myriad effects of climate change on the health of northern populations, in particular Indigenous groups who depend on natural resources for their well-being, ${ }^{124}$ the natural environment could be explored as a critical determinant of patient experiences for circumpolar populations.

Contextualising climate change as a determinant of patient experiences would necessitate a broader definition of what constitutes a 'health system'. This shift away from the framework that defines health systems as the sum of institutions and resources that deliver health services to a population requires a values-based conception grounded in the circumpolar context and especially in Indigenous knowledge. ${ }^{125} 126$ A multinational group previously identified and described nine values essential to integrating Indigenous ideologies into health system stewardship. ${ }^{12}$ Many of these values, such as cultural responsiveness, kinship and holism were echoed in much of the Indigenous literature included in this review. An expanded definition of health systems that not only takes into account the experiences of patients within healthcare facilities, but also of individuals enhancing their mental and physical health through on-the-land activities, would be more concordant with the circumpolar context. Additionally, it would enable capture of relevant information that could guide health system improvement, such as features in the community and natural environment that promote health. A panel of circumpolar health experts previously noted that moving away from the "narrow paradigm of 'health systems"' would be necessary to promote systemwide changes that support patients. ${ }^{125}$

Another critical component of making health systems more responsive to patient experiences is evaluation. Some regions rely on survey-based methodologies to collect patient feedback, while others use interviews, focus groups and other qualitative methodologies. In this study, we found that Scandinavia accounts for the majority of the quantitative studies, where patient satisfaction is often rated from predefined questionnaires. This is a method used to standardise evaluation of both patients' views on facilities, information and elements of treatment and to optimise and improve these areas. Qualitative studies are 
used to access a more nuanced knowledge of perceived satisfaction and experience of the individual or smaller groups. Qualitative methods were more frequently employed in studies originating in Canada, Alaska and Greenland. Notably, these were the same countries that reported most on Indigenous values and rural/remote themes. Additionally, climate change only came up as a factor in qualitative and mixed-method studies, which emphasises the importance of using qualitative methods to gather data on what is truly important to patients rather than solely relying on standardised surveys.

This discussion of aligning health systems more closely with patient needs benefits from a review of global literature from settings that share similar characteristics with circumpolar regions. Australia, which also has large rural and remote areas as well as an Indigenous population, has framed these discussions around patient experiences through the lens of cultural safety and has developed a monitoring framework that measures the cultural responsiveness and experiences of patients within the health system. ${ }^{127}$ Cultural safety is also emerging as a priority for circumpolar national and Indigenous governments and this framing of patient experiences warrants further consideration for circumpolar nations where colonial legacies are prominent in health services. Numerous studies of Aboriginal and Torres Strait Islander populations identified themes that this study also found to be relevant to circumpolar Indigenous groups, including traditional foods, language services, coordination of care and the importance of Indigenous staff members. ${ }^{128} 129$ These similarities suggest that changes meant to improve the experiences of patients within circumpolar health systems could be grounded by previous successes found elsewhere in the world.

This scoping review is both comprehensive and thorough; no restrictions limited the search by language or date of publication. This allowed for the broadest inclusion of relevant articles possible. Since 96 relevant articles were included in our review, we chose not to search for grey literature. We abstained from applying an external framework; this allowed for an analysis grounded more organically in the data provided and responsive to the circumpolar context.

Furthermore, nearly every article identified through the search criteria could be accessed in full text, and all full texts were reviewed by multiple authors. Similar redundancy was built into the data extraction process. These procedures ensured accuracy and rigour.

Based on this extensive review, next steps could involve the development of a circumpolar patient experience framework to guide future studies and comparative work in this area. Furthermore, a review of the existing grey literature would also be relevant, since, to our knowledge, not all research conducted in the circumpolar region is published in peer-reviewed journals. Additionally, this work could be further contextualised in sharing circles and other community-based participatory methodologies to enable validation of themes and additional comparison.
Such approaches would enable future studies and health systems to become more responsive to the needs of circumpolar populations.

Correction notice The article has been corrected since it is published. The previous table 2 format has been updated as Figure 5 .

Acknowledgements We would like to acknowledge the librarians Sandra Campbell at the University of Alberta and Anne Faber Hansen at the University of Southern Denmark who helped to set up a comprehensive and detailed search and assisting us in accessing articles. We would also like to acknowledge the Institute for Circumpolar Health Research, which provided administrative support. Finally, we thank Fulbright Canada and the Dartmouth Center for Health Equity Lombard Fellowship for supporting two authors (NFH and KJ).

Collaborators Sandra Campbell, University of Alberta Health Sciences Library; Anne Faber Hansen, University Library of Southern Denmark.

Contributors Conceived and designed the review: $\mathrm{Cl}, \mathrm{NFH}, \mathrm{SC}, \mathrm{CVLL}, \mathrm{KJ}, \mathrm{NLH}$. Screening and reviewing articles and data: $\mathrm{NFH}, \mathrm{Cl}, \mathrm{KJ}$, NLH. Data extraction: NFH, $\mathrm{Cl}$. Primary draft of the manuscript: $\mathrm{Cl}, \mathrm{NFH}$. Revising the manuscript: $\mathrm{Cl}, \mathrm{NFH}, \mathrm{SC}$, CVLL, NLH, KJ. All authors reviewed and approved the manuscript.

Funding Support was provided by Canadian Institutes of Health Research Strategy for Patient-Oriented Research, PICHIN Operations and Management grant \#143661.

Map disclaimer The depiction of boundaries on this map does not imply the expression of any opinion whatsoever on the part of BMJ (or any member of its group) concerning the legal status of any country, territory, jurisdiction or area or of its authorities. This map is provided without any warranty of any kind, either express or implied.

Competing interests None declared.

Patient consent for publication Not required.

Provenance and peer review Not commissioned; externally peer reviewed.

Data availability statement Data sharing not applicable as no data sets generated and/or analysed for this study. All data relevant to the study are included in the article or uploaded as supplementary information. Partial extraction table made available online. Full version available on reasonable request.

Open access This is an open access article distributed in accordance with the Creative Commons Attribution Non Commercial (CC BY-NC 4.0) license, which permits others to distribute, remix, adapt, build upon this work non-commercially, and license their derivative works on different terms, provided the original work is properly cited, appropriate credit is given, any changes made indicated, and the use is non-commercial. See: http://creativecommons.org/licenses/by-nc/4.0/.

ORCID iD

Christine Ingemann http://orcid.org/0000-0002-1390-4952

\section{REFERENCES}

1 Anhang Price R, Elliott MN, Zaslavsky AM, et al. Examining the role of patient experience surveys in measuring health care quality. Med Care Res Rev 2014;71:522-54.

2 Greenfield S, Kaplan SH, Ware JE, et al. Patients' participation in medical care: effects on blood sugar control and quality of life in diabetes. J Gen Intern Med 1988;3:448-57.

3 Rave N, Geyer M, Reeder B, et al. Radical systems change. innovative strategies to improve patient satisfaction. J Ambul Care Manage 2003;26:159-74.

4 Gee GC, Ford CL. Structural racism and health inequities: old issues, new directions. Du Bois Rev 2011;8:115-32.

5 Young TK. Circumpolar health indicators: sources, data, and maps. Int J Circumpolar Health 2008;67:1-130.

6 Huot S, Ho H, Ko A, et al. Identifying barriers to healthcare delivery and access in the Circumpolar North: important insights for health professionals. Int J Circumpolar Health 2019;78:1571385.

7 Mehus G, Bongo BA, Engnes Jl, et al. Exploring why and how encounters with the Norwegian health-care system can be considered culturally unsafe by North Sami-speaking patients and relatives: a qualitative study based on 11 interviews. Int $J$ Circumpolar Health 2019;78:1612703.

8 Jacklin KM, Henderson RI, Green ME, et al. Health care experiences of Indigenous people living with type 2 diabetes in Canada. CMAJ 2017;189:E106-12. 
9 Horrill T, McMillan DE, Schultz ASH, et al. Understanding access to healthcare among Indigenous peoples: a comparative analysis of biomedical and postcolonial perspectives. Nurs Inq 2018:25:e12237.

10 McNally M, Martin D. First Nations, Inuit and Metis health: considerations for Canadian health leaders in the wake of the Truth and Reconciliation Commission of Canada report. In: Healthcare management forum: 2017. Los Angeles, CA: SAGE Publications Sage CA, 2017: 30. 117-22.

11 Redvers N, Marianayagam J, Blondin B. Improving access to Indigenous medicine for patients in hospital-based settings: a challenge for health systems in northern Canada. Int J Circumpolar Health 2019;78:1577093.

12 Chatwood S, Paulette F, Baker GR, et al. Indigenous values and health systems stewardship in Circumpolar countries. Int J Environ Res Public Health 2017;14:1462

13 Redvers N, Blondin Be'sha. Traditional Indigenous medicine in North America: a scoping review. PLoS One 2020;15:e0237531.

14 Nair BV, Schuler R, Stewart S, et al. Self-reported barriers to healthcare access for rheumatoid arthritis patients in rural and Northern Saskatchewan: a mixed methods study. Musculoskeletal Care 2016;14:243-51.

15 Young K, Marchildon GP. A comparative review of circumpolar health systems. Int J Circumpolar Health 2012;71:1-112.

16 Hiratsuka V, Delafield R, Starks $\mathrm{H}$, et al. Patient and provider perspectives on using telemedicine for chronic disease management among native Hawaiian and Alaska native people. Int J Circumpolar Health 2013;72:21401.

17 Boman K, Olofsson M, Berggren P, et al. Robot-assisted remote echocardiographic examination and teleconsultation: a randomized comparison of time to diagnosis with standard of care referral approach. JACC Cardiovasc Imaging 2014;7:799-803.

18 Arksey H, O'Malley L. Scoping studies: towards a methodological framework. Int J Soc Res Methodol 2005;8:19-32.

19 Rich R, D'Hont T, Linton J, et al. Performance indicators for maternity care in a Circumpolar context: a scoping review. Int $J$ Circumpolar Health 2016;75:31470.

20 Redvers J, Bjerregaard P, Eriksen $\mathrm{H}$, et al. A scoping review of Indigenous suicide prevention in circumpolar regions. Int $\mathrm{J}$ Circumpolar Health 2015;74:27509.

21 Galloway T, Blackett H, Chatwood S, et al. Obesity studies in the circumpolar inuit: a scoping review. Int $J$ Circumpolar Health 2012;71:18698.

22 GRID-Arendal. Indigenous peoples of the arctic, 2016. Available: https://www.arcgis.com/apps/Cascade/index.html?appid=2228 ac6bf45a4cebafc1c3002ffef0c4 [Accessed Jul 2020].

23 Arctic Council. Indigenous peoples' secretariat Troms $\varnothing$, Norway, 2020. Available: https://www.arcticpeoples.com/ [Accessed Jun 2020].

24 Covidence. Better systematic review management, 2020. Available: https://www.covidence.org/home [Accessed May 2020]

25 O'Neil JD. The cultural and political context of patient dissatisfaction in cross-cultural clinical encounters: a Canadian Inuit study. Med Anthropol Q 1989;3:325-44.

26 Sigurthardottir AK. Satisfaction among ambulatory surgery patients in two hospitals in Iceland. J Nurs Manag 1996:4:69-74.

27 Bragadóttir H. A descriptive study of the extent to which selfperceived needs of parents are Met in paediatric units in Iceland. Scand J Caring Sci 1999;13:201-7.

28 Gottfredsdottir H, Steingrímsdóttir Póra, Björnsdóttir A, et al. Content of antenatal care: does it prepare women for birth? Midwifery 2016;39:71-7.

29 Jonsdottir T, Gunnarsdottir S, Jonsdottir H. Chronic pain-related patient-provider communication: the significance of health related quality of life and satisfaction. Scand J Pain 2015;8:50.

30 Snorradóttir MH, Arnar DO, Ólafsson RF, et al. [Patient satisfaction with care and interaction with staff in the Acute Cardiac Unit at Landspitali - The National University Hospital of Iceland]. Laeknabladid 2014;100:385-90.

31 Jonsdottir T, Gunnarsdottir S, Oskarsson GK, et al. Patients' perception of Chronic-Pain-Related patient-provider communication in relation to sociodemographic and pain-related variables: a crosssectional nationwide study. Pain Manag Nurs 2016;17:322-32.

32 Zoëga S, Sveinsdottir H, Sigurdsson GH, et al. Quality pain management in the hospital setting from the patient's perspective. Pain Pract 2015;15:236-46.

33 Sigurdardottir VL, Gamble J, Gudmundsdottir B, et al. The predictive role of support in the birth experience: a longitudinal cohort study. Women Birth 2017;30:450-9.

34 Hjörleifsdóttir E, Hallberg IR, Gunnarsdóttir ED. Satisfaction with care in oncology outpatient clinics: psychometric characteristics of the Icelandic EORTC IN-PATSAT32 version. J Clin Nurs 2010;19:1784-94.

35 Baldursdottir $\mathrm{G}$, Jonsdottir $\mathrm{H}$. The importance of nurse caring behaviors as perceived by patients receiving care at an emergency department. Heart Lung 2002;31:67-75.

36 Sigurdardottir AO, Garwick AW, Svavarsdottir EK. The importance of family support in pediatrics and its impact on healthcare satisfaction. Scand J Caring Sci 2017;31:241-52.

37 Halldórsdóttir S, Karlsdóttir SI. Empowerment or discouragement: women's experience of caring and uncaring encounters during childbirth. Health Care Women Int 1996;17:361-79.

38 Hjörleifsdóttir E, Hallberg IR, Gunnarsdóttir ED, et al. Living with cancer and perception of care: icelandic oncology outpatients, a qualitative study. Support Care Cancer 2008;16:515-24.

39 Fridfinnsdottir EB. Icelandic women's identifications of stressors and social support during the diagnostic phase of breast cancer. $J$ Adv Nurs 1997;25:526-31.

40 Thorsteinsson LS. The quality of nursing care as perceived by individuals with chronic illnesses: the magical touch of nursing. $J$ Clin Nurs 2002;11:32-40.

41 Biering $\mathrm{P}$, Jensen $\mathrm{VH}$. The concept of patient satisfaction in adolescent psychiatric care: a qualitative study. J Child Adolesc Psychiatr Nurs 2011;24:3-10.

42 Löve L, Traustadóttir R, Rice JG. Trading autonomy for services: perceptions of users and providers of services for disabled people in Iceland. Alter 2018;12:193-207.

43 Jóhannesdóttir S, Hjörleifsdóttir E. Communication is more than just a conversation: family members' satisfaction with end-of-life care. Int J Palliat Nurs 2018;24:483-91.

44 Traulsen JM, Almarsdóttir AB, Björnsdóttir I. The lay user perspective on the quality of pharmaceuticals, drug therapy and pharmacy services--results of focus group discussions. Pharm World Sci 2002;24:196-200.

45 Arnadottir U, Egilson ST. Evaluation of therapy services with the measure of processes of care (MPOC-20): the perspectives of Icelandic parents of children with physical disability. J Child Health Care 2012;16:62-74

46 Svavarsdóttir SJ, Júlíusdóttir S, Lindqvist R. A holistic view in psychiatric rehabilitation: the effects of structure in psychiatric institutions. J Soc Work Disabil Rehabil 2013;12:272-94.

47 Ingadottir B, Johansson Stark A, Leino-Kilpi H, et al. The fulfilment of knowledge expectations during the perioperative period of patients undergoing knee arthroplasty -- a Nordic perspective. J Clin Nurs 2014;23:2896-908.

48 Lundgren I, Karlsdottir SI, Bondas T. Long-Term memories and experiences of childbirth in a Nordic context-a secondary analysis. Int J Qual Stud Health Well-being 2009;4:115-28.

49 Sjöblom I, Idvall E, Lindgren $\mathrm{H}$, et al. Creating a safe havenwomen's experiences of the midwife's professional skills during planned home birth in four Nordic countries. Birth 2014;41:100-7.

50 Risberg T, Bremnes RM, Wist E, et al. Communicating with and treating cancer patients: how does the use of non-proven therapies and patients' feeling of mental distress influence the interaction between the patient and the hospital staff. Eur $J$ Cancer 1997;33:883-90.

51 Bekkelund SI, Ofte HK, Alstadhaug KB. Patient satisfaction with conventional, complementary, and alternative treatment for cluster headache in a Norwegian cohort. Scand J Prim Health Care 2014:32:111-6.

52 Wåhlberg $\mathrm{H}$, Braaten T, Broderstad AR. Impact of referral templates on patient experience of the referral and care process: a cluster randomised trial. BMJ Open 2016;6:e011651.

53 Bekkelund SI, Salvesen R. [Patient satisfaction with assessment of headache by specialist consultation]. Tidsskr Nor Laegeforen 2006;126:1595-7.

54 Garratt AM, Danielsen K, Forland O, et al. The patient experiences questionnaire for out-of-hours care (PEQ-OHC): data quality, reliability, and validity. Scand J Prim Health Care 2010;28:95-101.

55 Olsen B, Fylkesnes K. The health survey in Finnmark-satisfaction with hospital services. Tidsskrift for den Norske laegeforening: tidsskrift for praktisk medicin 1993;113:2081-4.

56 Lian OS, Wilsgaard T. Patient satisfaction in general practice before and after the introduction of a list patient system. Tidsskrift for den Norske Laegeforening 2004;124:655-8.

57 Olsen B, Fylkesnes K. The health survey in Finnmark-how is the population satisfied with community health services? Tidsskrift for den Norske laegeforening: tidsskrift for praktisk medicin 1991:111:1385-9.

58 Sørlie T, NergÅrd J-I. Treatment satisfaction and recovery in Saami and Norwegian patients following psychiatric hospital treatment: a comparative study. Transcult Psychiatry 2005;42:295-316. 
59 Nystad T, Melhus M, Lund E. Sami speakers are less satisfied with general practitioners' services. Int J Circumpolar Health 2008;67:116-23.

60 Pedersen S, Holand U, Psychol C. Tele-endoscopic otorhinolaryngological examination: preliminary study of patient satisfaction. Telemed J 1995;1:47-52.

61 Müller KI, Alstadhaug KB, Bekkelund SI. Headache patients satisfaction with telemedicine: a 12-month follow-up randomized non-inferiority trial. Eur J Neurol 2017;24:807-15.

62 Moseng D. Teledermatology-the north Norwegian experience. J Norwegian Med Assoc 2000;120:1893-5.

63 Garcia BH, Storli SL, Småbrekke L. A pharmacist-led follow-up program for patients with coronary heart disease in North Norway-a qualitative study exploring patient experiences. BMC Res Notes 2014;7:197.

64 Hågensen G, Nilsen G, Mehus G, et al. The struggle against perceived negligence. A qualitative study of patients' experiences of adverse events in Norwegian hospitals. BMC Health Serv Res 2018; $18: 302$.

65 Trumpy JH. Should hospital patients get copies of their medical reports? Tidsskrift for den Norske Laegeforening 2002;4:394-6.

66 Klausen RK, Blix BH, Karlsson M, et al. Shared decision making from the service users' perspective: A narrative study from community mental health centers in northern Norway. Soc Work Ment Health 2017:15:354-71.

67 Dagsvold I, Møllersen S, Stordahl V. What can we talk about, in which language, in what way and with whom? SAMI patients' experiences of language choice and cultural norms in mental health treatment. Int J Circumpolar Health 2015;74:26952.

68 Hanssen I, Kuven BM. Moments of joy and delight: the meaning of traditional food in dementia care. J Clin Nurs 2016;25:866-74.

69 Hanssen I. The influence of cultural background in intercultural dementia care: exemplified by SAMI patients. Scand J Caring Sci 2013;27:231-7.

70 Holtan A. Patient reactions to specialist telemedicine consultations-a sociological approach. J Telemed Telecare 1998;4:206-13.

71 Blix BH, Hamran T. "They take care of their own": healthcare professionals' constructions of Sami persons with dementia and their families' reluctance to seek and accept help through attributions to multiple contexts. Int J Circumpolar Health 2017;76:1328962.

72 Rotvold G-H, Knarvik U, Johansen MA, et al. Telemedicine screening for diabetic retinopathy: staff and patient satisfaction. $J$ Telemed Telecare 2003;9:109-13.

73 Lövgren G, Sandman PO, Engström B, et al. The view of caring among patients and personnel. Scand J Caring Sci 1998;12:33-41.

74 Lövgren G, Eriksson S, Sandman P-O. Effects of an implemented care policy on patient and personnel experiences of care. Scand $J$ Caring Sci 2002;16:3-11.

75 Franzén C, Björnstig U, Jansson L, et al. Injured road users' experience of care in the emergency department. $J$ Clin Nurs 2008;17:726-34.

76 Högberg U, Lynöe N, Wulff M. Cesarean by choice? empirical study of public attitudes. Acta Obstet Gynecol Scand 2008;87:1301-8.

77 Andén A, André M, Rudebeck CE. What happened? GPs' perceptions of consultation outcomes and a comparison with the experiences of their patients. Eur J Gen Pract 2010;16:80-4.

78 Hildingsson I, Cederlöf L, Widén S. Fathers' birth experience in relation to midwifery care. Women Birth 2011;24:129-36.

79 Haines HM, Hildingsson I, Pallant JF, et al. The role of women's attitudinal profiles in satisfaction with the quality of their antenatal and intrapartum care. J Obstet Gynecol Neonat Nurs 2013:42:428-41.

80 Sandlund M, Hansson L. Patient satisfaction in a comprehensive sectorized psychiatric service: study of a 1-year-treated incidence cohort. Nordic J Psychiatry 1999;53:305-12.

81 Gafvels C, Lithner PG. Insulin-treated diabetic patients. Use of, experience of and attitudes to diabetes care. Europ $J$ Public Health 1996;6:262-9.

82 Daerga L, Sjölander P, Jacobsson L, et al. The confidence in health care and social services in northern Sweden - a comparison between reindeer-herding SAMI and the non-Sami majority population. Scand J Public Health 2012;40:516-22.

83 Gustafsson S, Martinsson J, Wälivaara B-M, et al. Influence of selfcare advice on patient satisfaction and healthcare utilization. $J \mathrm{Adv}$ Nurs 2016;72:1789-99.

84 Ljung S, Olsson C, Rask M, et al. Patient experiences of a theorybased lifestyle-focused group treatment in the prevention of cardiovascular diseases and type 2 diabetes. Int J Behav Med 2013:20:378-84.
85 Aléx J, Lundgren P, Henriksson O, et al. Being cold when injured in a cold environment--patients' experiences. Int Emerg Nurs 2013;21:42-9.

86 Wiklund M, Fjellman-Wiklund A, Stålnacke B-M, et al. Access to rehabilitation: patient perceptions of inequalities in access to specialty pain rehabilitation from a gender and intersectional perspective. Glob Health Action 2016;9:31542.

87 Gustafsson S, Wälivaara B-M, Gabrielsson S. Patient satisfaction with telephone nursing: a call for calm, clarity, and competence. J Nurs Care Qual 2019;35:E6-11.

88 Aléx J, Karlsson S, Saveman B-I. Patients' experiences of cold exposure during ambulance care. Scand J Trauma Resusc Emerg Med 2013;21:44.

89 Skär L, Söderberg S. Patients' complaints regarding healthcare encounters and communication. Nurs Open 2018;5:224-32.

90 Lindberg I, Christensson K, Öhrling K. Parents' experiences of using videoconferencing as a support in early discharge after childbirth. Midwifery 2009;25:357-65.

91 Afifi TO, Cox BJ, Sareen J. Perceived need and help-seeking for mental health problems among Canadian provinces and territories. Can J Commun Ment Health 2005;24:51-61.

92 Worthington C, Jackson R, Mill J, et al. Hiv testing experiences of Aboriginal youth in Canada: service implications. AIDS Care 2010;22:1269-76.

93 Cano JK, Foster AM. "They made me go through like weeks of appointments and everything": Documenting women's experiences seeking abortion care in Yukon territory, Canada. Contraception 2016:94:489-95.

94 Arnaert A, Schaack G. Cultural awareness of Inuit patients' experiences with emergency nursing care. Accid Emerg Nurs 2006:14:97-103.

95 Oosterveer TM, Young TK, Michiel Oosterveer T. Primary health care accessibility challenges in remote Indigenous communities in Canada's North. Int J Circumpolar Health 2015;74:29576.

96 Bird SM, Wiles JL, Okalik L, et al. Living with diabetes on Baffin island. Can J Public Health 2008:99:17-21.

97 Fraser SL, Nadeau L. Experience and representations of health and social services in a community of Nunavik. Contemp Nurse 2015:51:286-300.

98 Hanrahan MC. Identifying the needs of Innu and Inuit patients in urban health settings in Newfoundland and Labrador. Can J Public Health 2002;93:149-52.

99 Mendez I, Jong M, Keays-White D, et al. The use of remote presence for health care delivery in a northern Inuit community: a feasibility study. Int J Circumpolar Health 2013;72:21112.

100 Quick R, Bashshur R. Three perspectives on community health aides: surveys of health aides, consumers and providers in Western Alaska. Arctic Med research 1991:161-5.

101 Hagopian A, House P, Dyck S, et al. The use of community surveys for health planning: the experience of 56 northwest rural communities. J Rural Health 2000;16:81-90.

102 DeCourtney CA. Alaska native community assessment: health care services, knowledge of health issues, and health education. Int $J$ Circumpolar Health 1998:57:656-64.

103 Lanier AP, Kelly JJ, Holck P. Pap prevalence and cervical cancer prevention among Alaska native women. Health Care Women Int 1999;20:471-86.

104 Driscoll D, Dotterrer B, Miller J, et al. Assessing the influence of health on rural outmigration in Alaska. Int J Circumpolar Health 2010;69:528-44.

105 DeMay DA. The experience of being a client in an Alaska public health nursing home visitation program. Public Health Nurs 2003;20:228-36.

106 Parret VC. Meeting the needs of breast cancer survivors in Alaska: survivors' and healthcare providers' perspectives. University of Alaska, 2011

107 Wetterhall S, Burrus B, Shugars D, et al. Cultural context in the effort to improve oral health among Alaska native people: the dental health aide therapist model. Am J Public Health 2011;101:1836-40.

108 Pellikka H, Lukkarinen H, Isola A. Potilaiden kasityksia hyvasta hoidosta yhteispaivystyksessa [Patients' views of good nursing care in an emergency unit]. Hoitotiede 2003;15:166-79.

109 Oikarinen A, Kangas E, Repola H, et al. Patient satisfaction with health care services via videoconferencing. Proc Hum Factors Ergon Soc Annu Meet 2000;44:177-80.

110 Mielonen ML, Ohinmaa A, Moring J, et al. Psychiatric inpatient care planning via telemedicine. J Telemed Telecare 2000;6:152-7.

111 Elsass P, Christensen HP, Falhof $\mathrm{J}$, et al. [Greenlanders in hospital. An interview study of communication between patients and therapists, satisfaction and therapeutic preferences]. Ugeskr Laeger 1994:156:1794-7. 
112 Montgomery-Andersen RA, Willén H, Borup I. 'There was no other way things could have been.' Greenlandic women's experiences of referral and transfer during pregnancy. Anthropol Med 2010;17:301-13.

113 Hounsgaard L, Augustussen M, Møller H, et al. Women's perspectives on illness when being screened for cervical cancer. Int J Circumpolar Health 2013;72:21089.

114 Aagaard T. Patient involvement in healthcare professional practice - a question about knowledge. Int J Circumpolar Health 2017;76:1403258.

115 Fotaki M. Users' perceptions of health care reforms: quality of care and patient rights in four regions in the Russian Federation. Soc $\mathrm{Scl}$ Med 2006;63:1637-47.

116 Heiberg E, Skurtveit S. Voices of women in North-West Russia - About maternity care. Tidsskrift for den Norske Laegeforening 2005;125:2826-8

117 Kuznetsov VN, Grjibovski AM, Mariandyshev AO, et al. Hopelessness as a basis for tuberculosis diagnostic delay in the Arkhangelsk region: a grounded theory study. BMC Public Health 2013;13:712.

118 Askham J, Kuhn L, Frederiksen K, et al. The information and support needs of Faroese women hospitalised with an acute coronary syndrome. J Clin Nurs 2010;19:1352-61.

119 Ford JD, Berrang-Ford L, King M, et al. Vulnerability of Aboriginal health systems in Canada to climate change. Glob Environ Change 2010;20:668-80.

120 Costello A, Maslin M, Montgomery H, et al. Global health and climate change: moving from denial and catastrophic fatalism to positive action. Philos Trans A Math Phys Eng Sci 2011;369:1866-82.
121 Parkinson AJ. Sustainable development, climate change and human health in the Arctic. Int J Circumpolar Health 2010;69:99-105.

122 Lancet and the University College London Institute for Global Health Commission. Managing the health effects of climate change. Lancet 2009;373.

123 Bourque F, Willox AC. Climate change: the next challenge for public mental health? Int Rev Psychiatry 2014;26:415-22.

124 Parkinson AJ, Evengård B. Climate change, its impact on human health in the Arctic and the public health response to threats of emerging infectious diseases. Glob Health Action 2009;2:2075.

125 Chatwood S, Bytautas J, Darychuk A, et al. Approaching a collaborative research agenda for health systems performance in Circumpolar regions. Int J Circumpolar Health 2013;72:21474.

126 Cueva K, Guistini S, Healey G, et al. From resilient to thriving: supporting health and well-being in Arctic communities. 2019 policy Brief-Fulbright Arctic initiative symposium: Fulbright Arctic initiative program cohort II (2018-19), 2019.

127 Australian Institute of Health and Welfare. Cultural safety in health care for Indigenous Australians: monitoring framework. Canberra: Australian Institute of Health and Welfare, 2020.

128 Green M, Anderson K, Griffiths K, et al. Understanding Indigenous Australians' experiences of cancer care: stakeholders' views on what to measure and how to measure it. BMC Health Serv Res 2018;18:982.

129 Wotherspoon C, Williams CM. Exploring the experiences of Aboriginal and Torres Strait Islander patients admitted to a metropolitan health service. Aust Health Rev 2019;43:217-23. 